\title{
Isolation and Functional Analysis of Flowering Locus $T$ in Tree Peonies (PsFT)
}

\author{
Hua Zhou \\ Landscape Architecture College of Beijing Forestry University, National Flower Engineering \\ Research Center, Beijing 100083, China; and Institute of Biology and Resources, Jiangxi Academy of \\ Sciences, Nanchang 330096, China \\ Fang-Yun Cheng ${ }^{1}$ and Jing Wu \\ Landscape Architecture College of Beijing Forestry University, National Flower Engineering \\ Research Center, Beijing 100083, China \\ Chaoying $\mathbf{H e}^{1}$ \\ State Key Laboratory of Systematic and Evolutionary Botany, Institute of Botany, Chinese Academy of \\ Sciences, Beijing 100093, China
}

\begin{abstract}
AdDitional INDEX words. flowering time, reblooming, Paeonia $\times$ lemoinei, Paeonia $\times$ suffruticosa
Abstract. Arabidopsis thaliana Flowering locus T (FT) homologs have been shown to be sufficient to trigger flowering and to regulate flowering time in a wide range of plants. However, such a homologue for the perennial ornamental shrub tree peony has not yet been characterized. In this study, we isolated $P S F T$, which is a closely related $F T$ homolog from reblooming [Paeonia $\times$ lemoinei 'High Noon' (HN)] and nonreblooming [P. Xsuffruticosa 'Luo Yang Hong' (LYH)] cultivars of tree peonies, and identified its potential role in the regulation of flowering time. The PsFT alleles from the two cultivars encode the same protein, which indicates that the polymorphisms observed in the coding region do not contribute to the distinct flowering phenotypes of HN and LYH. Comparative analyses of the PsFT expression patterns in HN and LYH indicated that PSFT might be associated with reblooming. Transgenic $A$. thaliana plants ectopically expressing PSFT exhibited a phenotype that included significantly early flowering compared with the wild-type (WT) plants. Taken together, our data provide valuable clues for shortening the juvenile periods and extending the flowering periods of perennial woody plants, such as tree peonies.
\end{abstract}

A considerable number of studies of $A$. thaliana have revealed that the flowering time is regulated by both environmental and endogenous cues. The input cues are integrated into the floral transition via several genes known as floral pathway integrators, such as FT (Parcy, 2005; Simpson and Dean, 2002). FT is a major component of florigen and has been shown to be sufficient to trigger flowering (Turck et al., 2008). In A. thaliana, mutations in FT cause a delay in flowering, and the overexpression of FT causes early flowering (Kardailsky et al., 1999). FT proteins move from the leaves to the shoot apical meristem (SAM) to induce flowering (Jaeger and Wigge, 2007). At the SAM, FT forms a complex with the basic leucine zipper (bZIP) protein Flowering locus $D(F D)$ and upregulates the floral meristem identity gene Apetalal (AP1) (Abe et al., 2005; An et al., 2004).

Because of the long juvenile phase, woody plant flowering studies are important for accelerating the breeding process by shortening the juvenile phase. Based on studies of $A$. thaliana, examinations of flowering in perennial woody plants have enabled progress in unveiling the molecular mechanisms of flowering. FT-like genes have been identified and shown to induce flowers in Populus (Hsu et al., 2006; Igasaki et al., 2008). The FT-like MdFT1 and MdFT2 genes of apple (Malus $\times$ domestica) have also exhibited the potential to act as floral

Received for publication 18 Dec. 2014. Accepted for publication 18 Feb. 2015. This study was supported by the National High Technology Research and Development Program of China (863 Program, 2011AA100207).

We thank Silan Dai for kindly providing the pBI121 and EHA105.

${ }^{1}$ Corresponding author. E-mail: chengfy8@263.net; chaoying@ibcas.ac.cn. promoters (Kittikorn et al., 2013; Kotoda et al., 2010). The FT homolog (CsFT) of Citrus controls floral induction and promotes flowering in trifoliate orange (Poncirus trifoliate) (Chica and Albrigo, 2013a, 2013b; Endo et al., 2005). The results of these studies suggest that $F T$ genes play key roles in the manipulation of flowering time, shorten the juvenile phase, and can be useful as research and breeding tools in perennial woody species (Zhang et al., 2010).

The tree peony (Paeonia section moutan) is a perennial woody shrub and an important ornamental crop that has been called the "king of flowers" in China and is cultivated worldwide (Wister, 1962). Because of its striking ornamental value, tree peony has contributed tremendously to gardens during its 1600 year history of cultivation (Gilmore et al., 2013; Li et al., 2011). In tree peony, the long juvenile phase of 4-6 years must be completed before flowering, which makes the ornamental and breeding cycle of tree peony slow. Flowering in tree peonies lasts only $4-5 \mathrm{~d}$ for a single flower and $20 \mathrm{~d}$ for the entire plant. The short and concentrated flowering period affects the economic value of the tree peony (Cheng, 2007; Kamenetsky et al., 2003). Flowering time has become one of the most relevant traits for increasing the value of tree peonies as ornamental landscape plants and promoting the peony industry.

Recently, we performed floral transcriptome sequencing and characterized a series of unigenes from tree peony that included an FT homolog [PSFT (Wu et al., 2014; Zhou et al., 2013)]. $P S F T$ potentially has a role in flowering based on transcriptomic comparisons between the reblooming $P$. $\times$ lemoinei 'HN' and the nonreblooming $P$. Xsuffruticosa LYH. However, the FT 
Table 1. Phenotype of $\mathrm{T}_{2}$ transgenic Arabidopsis thaliana plants with Flowering locus $T(F T)$ from tree peonies $(P S F T)$.

\begin{tabular}{lcccc}
\hline & $\begin{array}{c}\text { Rosette leaves } \\
\text { at bolting (no.) }\end{array}$ & $\begin{array}{c}\text { Time to } \\
\text { bolting }(\mathrm{d})\end{array}$ & $\begin{array}{c}\text { Leaves at } \\
\text { flowering (no.) }\end{array}$ & $\begin{array}{c}\text { Time to } \\
\text { flowering (d) }\end{array}$ \\
Genotype $^{\mathrm{z}}$ & \multicolumn{4}{c}{ mean } \\
\hline WT & $11.17 \pm 0.75$ & $31.33 \pm 0.52$ & $16.67 \pm 0.82$ & $42.00 \pm 1.10$ \\
Vector & $11.50 \pm 0.55$ & $30.67 \pm 1.03$ & $15.83 \pm 0.75$ & $41.67 \pm 0.82$ \\
$35 S:: P S F T$-L1 & $4.00 \pm 0.00^{* *}$ & $20.50 \pm 1.05^{* *}$ & $5.67 \pm 0.52^{* *}$ & $27.00 \pm 0.63^{* *}$ \\
$35 S:: P S F T$-L2 & $4.16 \pm 0.41^{* *}$ & $19.67 \pm 0.52^{* *}$ & $6.00 \pm 0.63^{* *}$ & $26.17 \pm 0.75^{* *}$ \\
\hline
\end{tabular}

${ }^{\mathrm{z}} \mathrm{WT}=$ wild type.

** Significance at $P=0.01$.
(A)

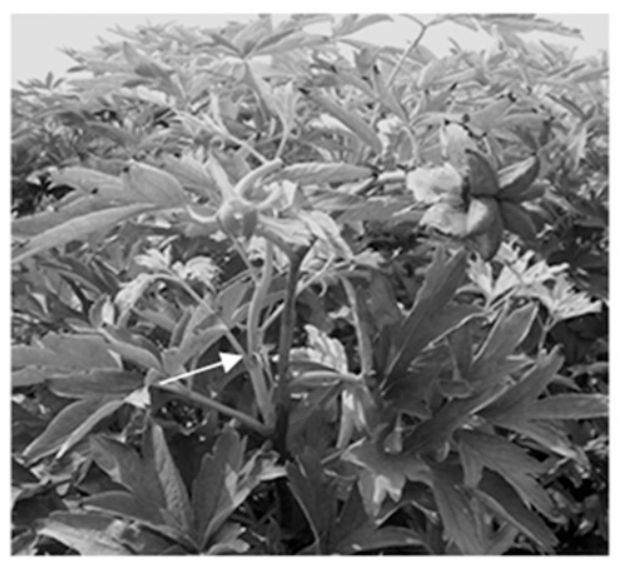

\section{(B)}

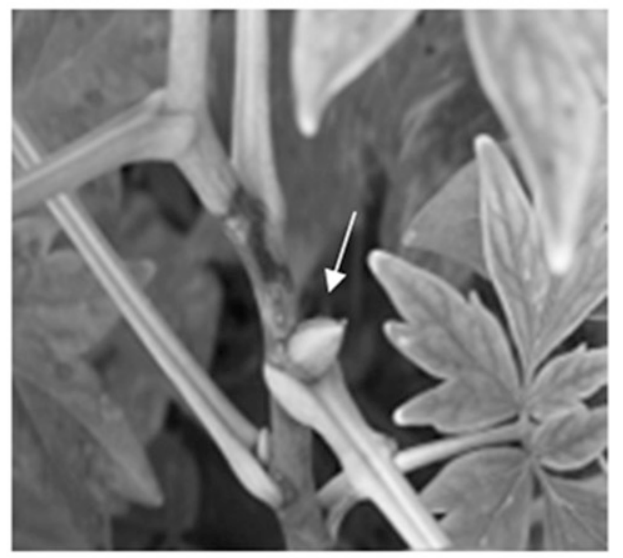

(C)

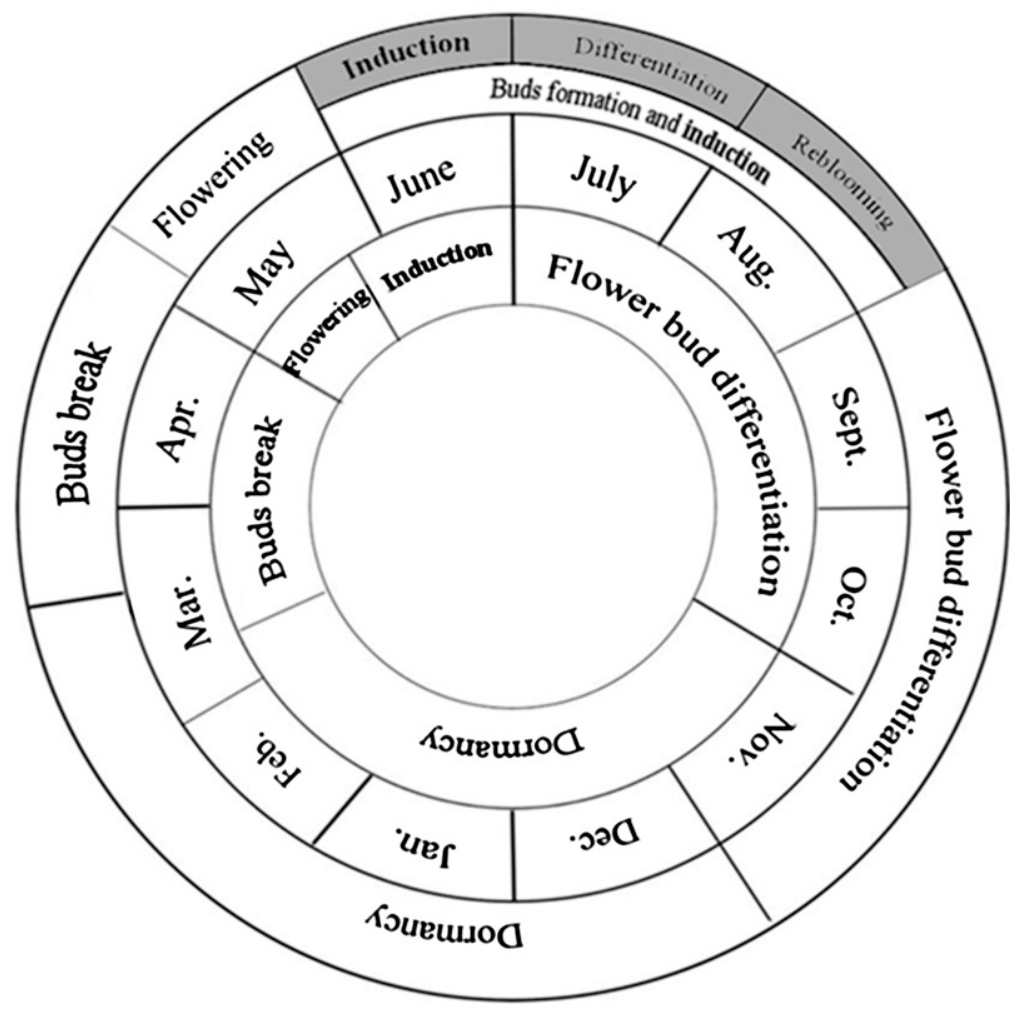

Fig. 1. Variations in the flowering in Paeonia $\times$ lemoinei 'High Noon' $(\mathrm{HN})$ and $P$. $\times$ suffruticosa 'Luo Yang Hong' (LYH). (A) A reblooming HN axillary shoot in August (white arrow). (B) The axillary bud of an LYH plant surrounded by bud scale in August (white arrow). (C) The annual cycles of growth and development for HN (outer ring) and LYH (inner ring). The shading indicates the process of reblooming in HN. homolog for tree peonies has not yet been characterized. We sought to further examine the role of $P S F T$ during flowering in tree peonies and the potential benefit of PsFT for shortening the juvenile growth phase and manipulating the flowering time of tree peonies. In this study, we isolated PsFT from $\mathrm{HN}$ and LYH and carried out a functional analysis. We found that $P s F T$ from the two cultivars of tree peony encode an identical protein and PsFT significantly promotes flowering in transgenic $A$. thaliana.

\section{Materials and Methods}

Plant materials. Two cultivars of tree peony, the reblooming $\mathrm{HN}$ and the nonreblooming $\mathrm{LYH}$, were grown in the Jiu Feng Forestry Experiment Station of the Beijing Forestry University of China. Different tissues, including the axillary buds (the scales and primordial leaves were removed), stems (distal to the buds), mature leaves (distal to the buds), and roots (fibrous roots), were collected at the same time from intact plants on 21 June 2013. The bud development process of tree peonies has previously been described (Barzilay et al., 2002; Wang and Zhang, 1987). All samples were immediately frozen in liquid nitrogen and subsequently stored at $-80^{\circ} \mathrm{C}$.

SyNTHESIS PSFT CDNA AND SEQUeNCE ANALYSIS. PsFT cDNAs were isolated using reverse transcription polymerase chain reaction (RTPCR) with total RNA extracted from the opened flowers. Total RNA was extracted with the RN38-EASYspin Plus (Aidlab, Beijing, China) and treated with RNase-free DNase I (Promega, Madison, WI). Total RNA purity was assessed using a spectrophotometer (Nanodrop 2000C; Thermo Fisher Scientific, Wilmington, DE), and the quality of the RNA was visualized using agarose gel electrophoresis. Firststrand cDNA was synthesized from $1 \mu \mathrm{g}$ of DNA-free RNA using the PrimeScript RT reagent kit (Takara, Tokyo, Japan). The PCR parameters were as follows: $94{ }^{\circ} \mathrm{C}$ for $5 \mathrm{~min}$; followed by 30 cycles of $30 \mathrm{~s}$ at $94^{\circ} \mathrm{C}, 30 \mathrm{~s}$ at $60^{\circ} \mathrm{C}$, and 1 min at $70^{\circ} \mathrm{C}$; and a final elongation 

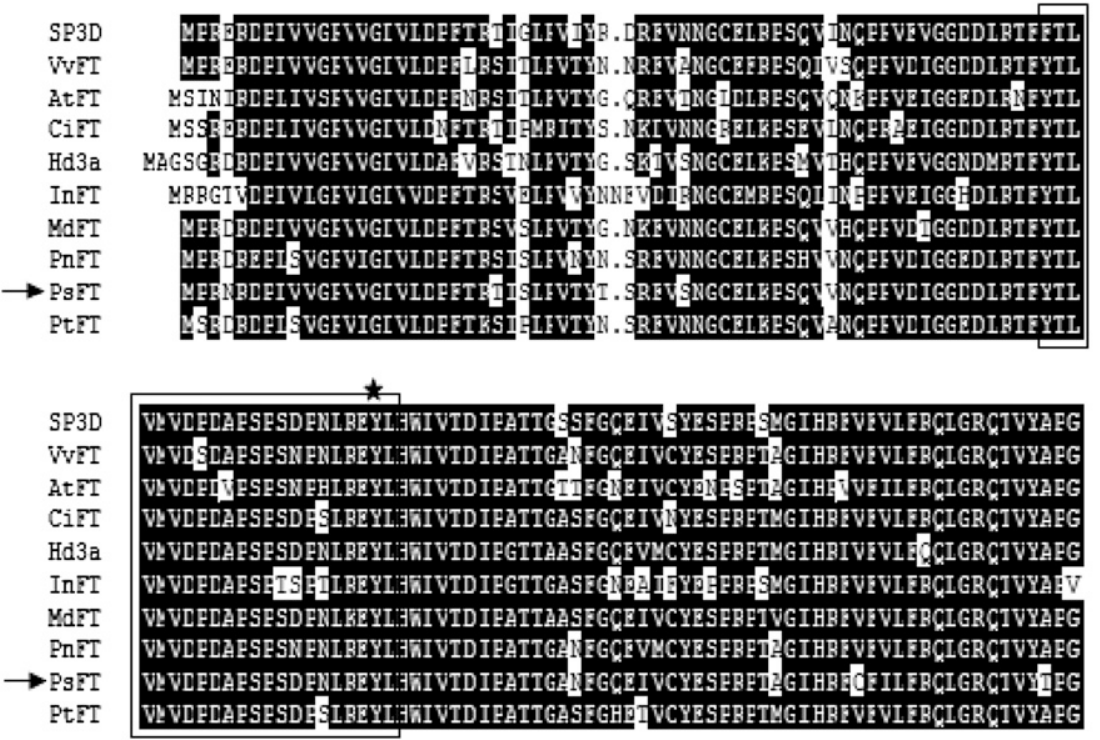

136
136
137
137
139
138
136
136
136
136
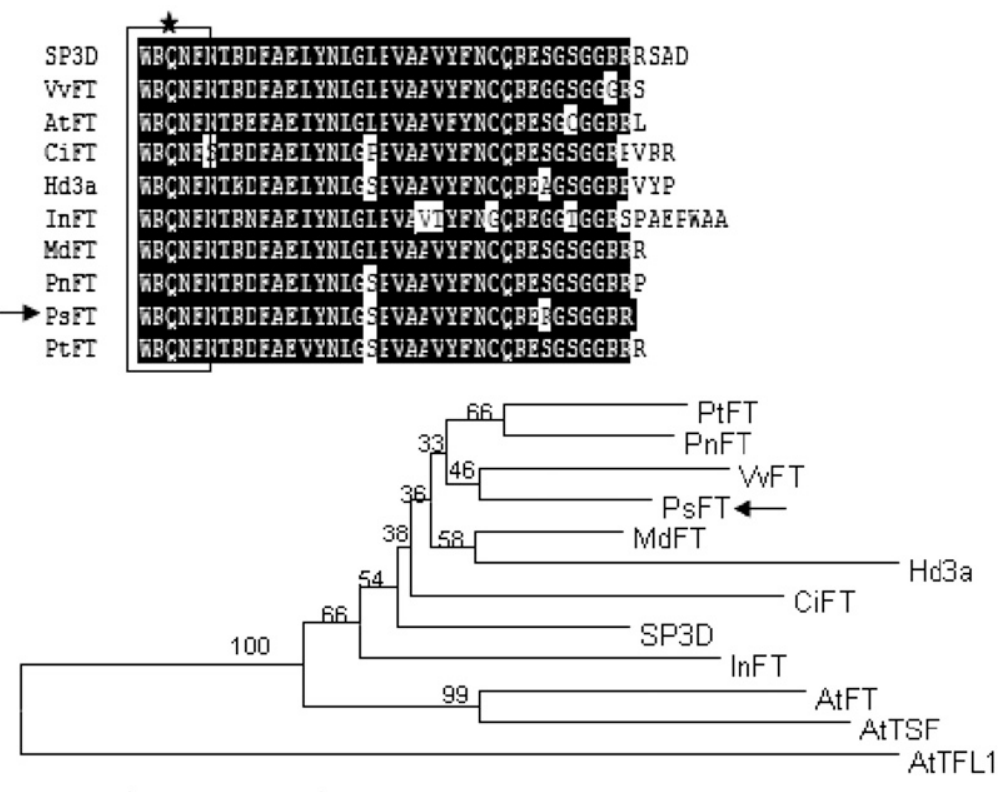

0.05

Fig. 2. Comparison of PsFT in tree peonies with its closely related homologs. (A) Alignments of the deduced protein sequences of PsFT and those of FT from other plants. The amino acids shown in black are identical across the 10 FT proteins. The asterisks and black squares represent the conserved domains of the PEBP family. (B) Phylogenetic analysis of the FT family proteins. The tree was constructed using deduced amino acid sequences, including those from A. thaliana (AtFT: NM_105222, AtTSF: NM_118156.1, AtTFL1: U77674.1), rice (Oryza sativa Japonica Group, Hd3a: NM_001063395), tomato (Solanum lycopersicum, SP3D: XM_004234835), poplar (Populus nigra, PnFT: AB106111.1, Populus tremula, PtFT: DQ387859), apple (Malus $\times$ domestica, MdFT: FJ555224.1), satsuma mandarin (Citrus unshiu, CsFT: AB027456), pharbitis (Ipomoea nil, InFT: EU178859), and grapevine (Vitis vinifera, VvFT: EF157728.1). AtTFL1 was used as the outgroup. The unit of the scale bar indicates the branch lengths ( 0.05 substitutions/site).
Q UANTITA TIVE REVERSE TRANSCRIPTION-POLYMERASE CHAIN REACTION. Expression of the PSFT genes in tissues during development was evaluated using quantitative real time reverse transcription polymerase chain reaction (qRT-PCR), which was performed on a Mini option Real-Time PCR instrument (BioRad, Hercules, CA) using $20 \mu \mathrm{L}$ of SYBR Premix EX Taq ${ }^{\mathrm{TM}}$ (Takara). The PCR program was initiated at $95^{\circ} \mathrm{C}$ for $30 \mathrm{~s}$, followed by 40 cycles of $95{ }^{\circ} \mathrm{C}$ for $5 \mathrm{~s}, 55^{\circ} \mathrm{C}$ for $30 \mathrm{~s}$, and $72{ }^{\circ} \mathrm{C}$ for $30 \mathrm{~s}$, and completed with a melting curve analysis for each reaction. The primers used in this study are described in Supplemental Table 1. The relative expression levels were calculated using the $2^{-\Delta \Delta \mathrm{Ct}}$ method (Livak and Schmittgen, 2001) and were normalized against the geometric averaging of the two reference genes Ubiquitin (UBQ) and Glyceraldehyde-3-phosphatedehydrogenase (GAPDH) (Wang et al., 2012). The qRT-PCR reactions were performed for three biological replicates from different plants with three technical repetitions per replicate. The data were analyzed using CFX manager 2.0 software (Bio-Rad).

Transgenic $\boldsymbol{A}$. ThaLIana ANALYSIS. Full-length $P S F T$ cDNA was amplified by PCR using the PSFT-XbaI and PSFT-SmaI pair of primers and was cloned into the binary vector pBI121 with expression driven by the cauliflower mosaic virus (CaMV) $35 \mathrm{~S}$ promoter. The sequences of PsFT-XbaI and PsFTSmaI are presented in Supplemental Table 1. The resulting construct, PSFT-pBI121, was transformed into Agrobacterium tumefaciens EHA105. A. thaliana (Col-0) transformation was performed using the floral dip method (Clough and Bent, 1998). The transformants ( $\mathrm{T}_{0}$ lines) from the dipped plants that survived in $1 / 2 \mathrm{MS}$ medium containing kanafor $10 \mathrm{~min}$ at $70{ }^{\circ} \mathrm{C}$. The primers for $P S F T$ are described in Supplemental Table 1. All amplified products were cloned into the pGEM-T vector (Promega), and putative positive clones were identified using PCR with the M13F and M13R sequencing primers (Supplemental Table 1). Homologs of PsFT were searched using the BLAST program of the National Center of Biotechnology Information (NCBI). Phylogenetic analyses were performed based on the neighbor-joining (N-J) model (Perriere and Gouy, 1996) with 1000 bootstrap replications using MEGA 5.0 software (The Biodesign Institute, Tempe, AZ) (Tamura et al., 2011). mycin $\left(100 \mu \mathrm{g} \cdot \mathrm{mL}^{-1}\right)$ were transplanted into a substrate consisting of vermiculite and nutrient soil $(\mathrm{v}: \mathrm{v}=1: 1)$ in a growth chamber at $22{ }^{\circ} \mathrm{C}$ under long-day (LD) conditions ( $16 \mathrm{~h}$ photoperiod, light intensity: $50 \mu \mathrm{mol} \cdot \mathrm{m}^{-2} \cdot \mathrm{s}^{-1}$ ). Morphological observation and expression analyses were performed on 8-10 plants from the second generation $\left(\mathrm{T}_{2}\right)$. The flowering time was measured by quantifying the number of leaves and the number of days until flowering. A one-way analysis of variance was performed with SPSS software (version 18.0; IBM, Armonk, NY). 
(A)

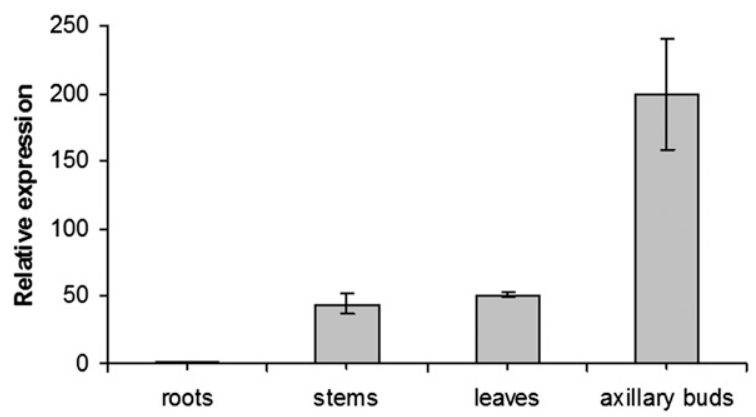

(B)

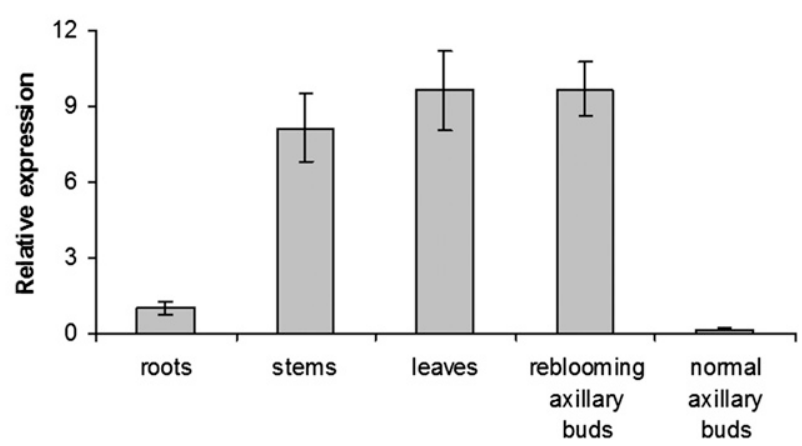

Fig. 3. PsFT tissue expression analysis in the $P$. $\times$ suffruticosa 'Luo Yang Hong' (LYH) and P. Xlemoinei 'High Noon' (HN). (A) PsFT transcripts in the roots, stems, leaves, and axillary buds in LYH. (B) PsFT transcripts in the roots, stems, leaves, reblooming axillary buds, and normal axillary buds in HN. The gene expression levels are expressed relative to roots. Data are means $\pm \operatorname{SE}(n=3)$.

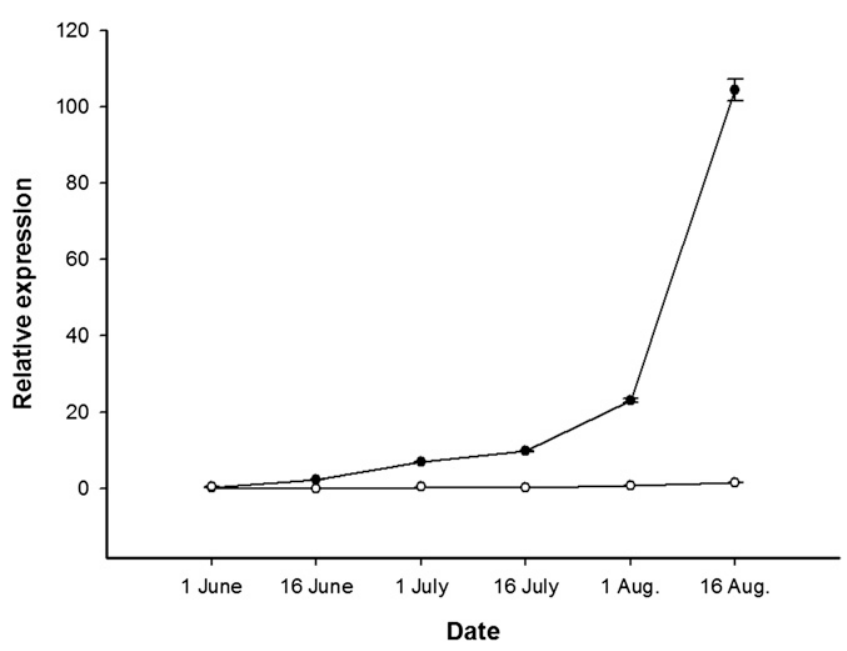

Fig. 4. Analysis of the expression patterns of $P S F T$ in the reblooming buds and normal buds of the $P$. $\times$ lemoinei 'High Noon'. The $x$-axis indicates the dates at which the shoot apexes were harvested from the reblooming buds (black dot) and the normal buds (open dot) in 2013. The gene expression levels are expressed relative to the first sample. Data are means $\pm \operatorname{SE}(n=3)$.

Total RNA was extracted from the transgenic $A$. thaliana lines and the WT plants. The gene-specific primers are presented in Supplemental Table 1. PCR was performed at 94 ${ }^{\circ} \mathrm{C}$ for $5 \mathrm{~min}$, followed by 30 cycles of $1 \mathrm{~min}$ at $94{ }^{\circ} \mathrm{C}, 1 \mathrm{~min}$ at the appropriate annealing temperature (Supplemental Table 1), $1 \mathrm{~min}$ at $72{ }^{\circ} \mathrm{C}$, and a final elongation of $15 \mathrm{~min}$ at $72{ }^{\circ} \mathrm{C}$.

\section{Results and Discussion}

VARIATION IN THE FLOWERING TIMES OF HN AND LYH. HN exhibits a stable reblooming trait under natural conditions that can cause flowering two or more times per year, whereas LYH and the majority of other peony cultivars flower once per year (Smith, 1997). Reblooming results from the sprouting of some axillary shoots and annual terminal shoots and subsequent development and reblooming after spring flowering (Fig. 1A). In LYH, after spring the axillary buds surrounded by bud scales entered the floral differentiation phase until winter dormancy (Fig. 1B). We examined the annual cycles of development and found different developmental process in both cultivars (Fig. 1C). There was a single floral transition in LYH in June and two floral transitions in $\mathrm{HN}$; the first occurred in June and resulted in reblooming, and the second occurred in August ahead of the next spring flowering.

Synthesis AND ChaRaCterization of PSFT cDNAs. Based on previously obtained sequences (NCBI accession number: SRP026412 and SRP026299), we generated the full-length cDNAs of the FT homologues (PsFT) of HN and LYH using RT-PCR. The two PsFT cDNAs (GenBank accession numbers KP198621 and KP198622) were the same length and contained four single nucleotide polymorphisms in 519 bp open reading frames (ORFs); however, the two PSFT genes encoded 173amino acid peptides with identical sequences [100\% identity (Supplemental Fig. 1)]. These peptides also exhibited high levels of amino acid identity with the $F T$ homologous genes of various plants, including AtFT in A. thaliana, $H d 3 a$ in rice (Oryza sativa), PnFT in poplar (Populus nigra), MdFT in apple, and $V v F T$ in grapevine (Vitis vinifera) $(77.71 \%, 79.33 \%$, $89.66 \%, 89.08 \%$, and $88.51 \%$, respectively). The amino acid sequence alignment revealed that PsFT contained a conserved domain with characteristics of the phosphatidylethanolamine binding protein (PEBP) family (Kikuchi et al., 2009) (Fig. 2A). The amino acids residues Tyr [Y (site 85)] and Gln [Q (site 140)] of FT were identified in PsFT; these residues are conserved resides of the PEBP family and are essential for the functional difference between FT and TERMINAL FLOWER1 (TFL1) (Hanzawa et al., 2005; Huang et al., 2012).

A N-J phylogenetic tree of PsFT in peonies and some PEBP family in various plants was constructed based on protein sequence alignments (Fig. 2B). The phylogenetic tree revealed that PsFT belonged to the FT cluster of the PEBP family and was related to FT proteins in deciduous perennial woody plants, such as grapevine and poplar. These results suggested that PsFT is a putative ortholog of $A$. thaliana $F T$.

EXPRESSION ANALYSES OF PSFT IN HN AND LYH. PSFT exhibited variation in the expression patterns in the shoot apices of the $\mathrm{HN}$ and LYH cultivars during floral initiation throughout 2012 (Zhou et al., 2013). To further investigate PSFT, tissue specificity analyses of $P S F T$ in HN and LYH were performed using qRT-PCR (Fig. 3). PsFT was detected at a high level in the flower buds and a low level in the roots, and this pattern is similar to the tissue expression patterns of poplar in June (Hsu et al., 2006). By 21 June 2013, floral induction had occurred in the axillary buds, and the vegetative growth tended to stop in LYH. At this point, PsFT expression in LYH was higher in the flower buds than in the leaves and stems and was expressed at a very low level in the roots (Fig. 3A). However, in HN, floral induction only occurred in the reblooming buds, which were sprouting and growing, and not in the normal axillary buds (i.e., 


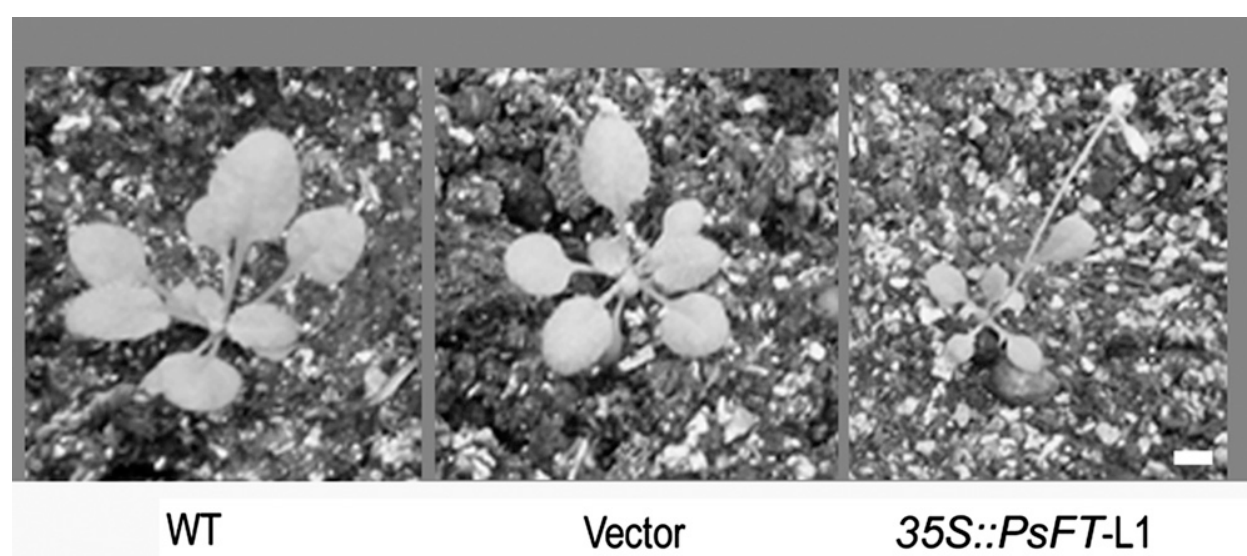

Fig. 5. The ectopic expression of PsFT in tree peonies induced early flowering in $A$. thaliana. A randomly selected transgenic line that constitutively expressed PSFT exhibited an early flowering phenotype relative to the wildtype (WT) and vector controls under long-day conditions. $\mathrm{Bar}=0.5 \mathrm{~cm}$.

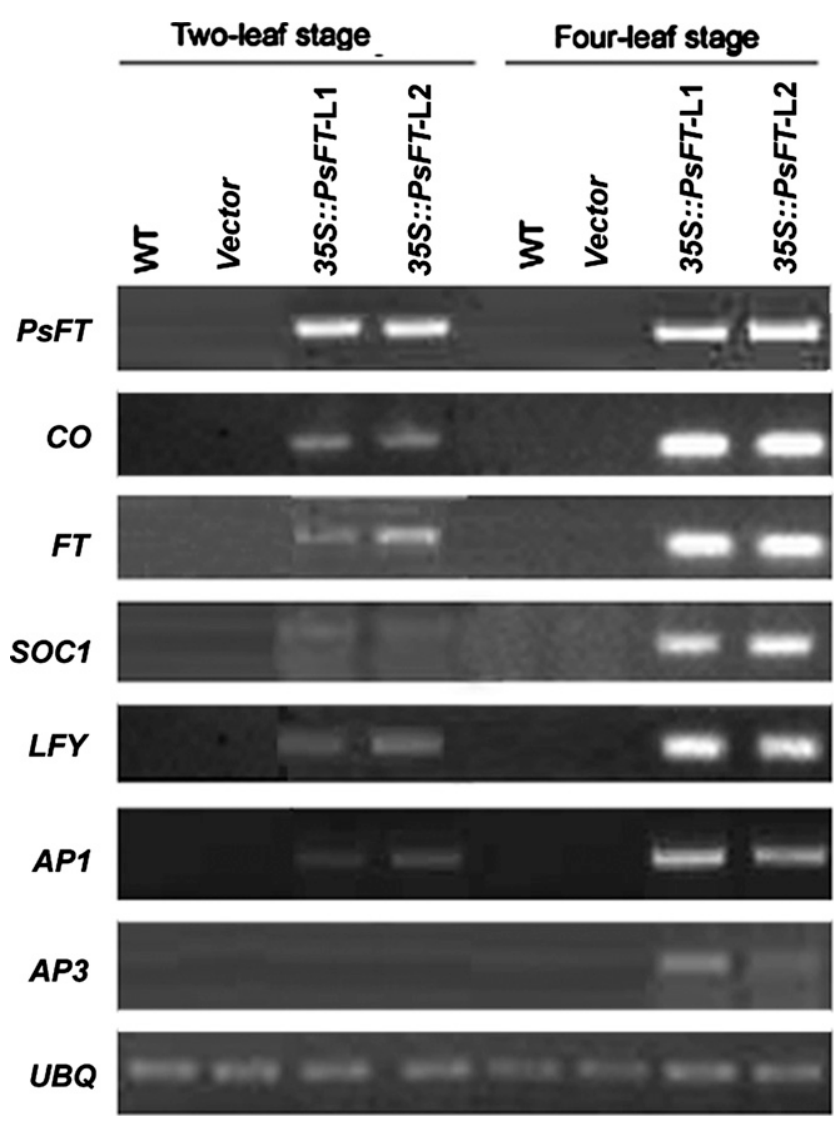

Fig. 6. Reverse transcription-polymerase chain reaction (RT-PCR) analyses of the accumulations of $P S F T, C O, F T, S O C 1, L F Y, A P 1$, and $A P 3$ transcripts at the two- and four-leaf stages of two transgenic $A$. thaliana plants. The expression of these genes in the wild-type (WT) $A$. thaliana and the transgenic plants harboring empty vector was also examined as controls. The $A$. thaliana $U B Q$ transcript was amplified to confirm that similar amounts of cDNA were used in the RT-PCR.

only leaf buds). PSFT was expressed at a high level in the reblooming axillary buds of $\mathrm{HN}$ and at a very low level in the normal axillary buds (Fig. 3B). PsFT accumulated in the leaves and stems at the same levels observed in the flower buds and was detected at background levels in the roots (Fig. 3B). These findings suggest that PsFT expression might be upregulated in the leaves, stems, and reblooming buds of the HN cultivar.
To investigate the association of PSFT with reblooming in the $\mathrm{HN}$ cultivar, we collected the reblooming and normal buds from the same plants and compared the PsFT transcript levels from induction to reblooming in 2013 (Fig. 4). In the normal buds, PsFT was maintained at a constantly low level during this period; however, in the reblooming buds, PsFT accumulated gradually to reach an $\approx 63$-fold greater level of mRNA in the flowers than in the normal buds by 16 Aug. This result revealed that high levels of the accumulation of $P S F T$ were associated with reblooming.

Reblooming characteristics could effectively extend the flowering period and enhance the commercial value of tree peony (Jiang et al., 2007). To date, various forced reblooming techniques for extending the flowering period in tree peonies have been considered; these techniques include pruning, GA treatment, defoliation, and moisture stress (Liu et al., 2002; Ren et al., 2004). However, little is known about the genetic regulation of the reblooming process due to the complex genetic background and inviable male gametes in the HN cultivar (Hao et al., 2013; He and Cheng, 2006). We previously reported on changes in expression of eight unigenes, including PSFT that were involved in floral pathways during the floral process in 2012 and found that reblooming might be a distinctive type of floral initiation in tree peony (Zhou et al., 2013). Furthermore, in this work, we found that PSFT accumulated in the leaves, stems, and flower buds of the HN cultivar and that the PsFT levels increased continuously in the reblooming buds (Figs. 3 and 4). These findings suggest that PsFT might be associated with the following aspects of the floral development process in $\mathrm{HN}$ : bud sprouting, vegetative growth, and reblooming. Similar observations have been reported in Populus, in which PtFT1 displayed peak expression in the period of floral initiation and low expression at growth cessation and bud set (Böhlenius et al., 2006), and FT showed a gradual but dramatic upregulation during chilling and bud burst (Rinne et al., 2011). These results indicate that $F T$ is a major regulatory factor in numerous developmental processes, including vegetative growth, flowering, and fruit set (Pin and Nilsson, 2012; Wigge, 2011) of woody plants. We believe that the regulation of PSFT and other flowering genes under optimal environmental conditions could potentially be used to induce reblooming or even continuous blooming in $\mathrm{HN}$.

ECtOPIC EXPRESSION OF PSFT in A. THALIANA. To further examine the role of $P S F T$ in floral initiation, we used a $35 S$ : PSFT construct and generated transgenic $A$. thaliana plants. Ten independent kanamycin-resistant $\mathrm{T}_{0}$ plants were obtained. All $\mathrm{T}_{0}$ plants flowered earlier than the WT and self-pollinated to generate first-generation seeds $\left(T_{1}\right)$. The seeds of each $T_{1}$ transgenic line were screened on 1/2 Murashige-Skoog (MS) containing kanamycin to generate second-generation seeds $\left(\mathrm{T}_{2}\right)$. The $\mathrm{T}_{2}$ lines were again screened on $1 / 2 \mathrm{MS}$ containing kanamycin, and the seedlings of the $T_{2}$ lines were used for phenotypic assessments of flowering time. All transgenic $A$. thaliana $\mathrm{T}_{2}$ lines exhibited earlier flowering time than the WT 
plants under the same growth conditions (Fig. 5A). Flowering time, in terms of numbers of leaves formed before bolting and flowering and the number of days from germination to bolting and flowering, differed significantly $(P<0.01)$ between the transgenic lines and controls (Fig. 5B). Under LD conditions, the transgenic lines bolted within $20 \mathrm{~d}$ of seed germination at the four-leaf (rosette) stage and flowered within $26 \mathrm{~d}$ of seed germination at the six-leaf stage, whereas the WT and vector controls bolted within $30 \mathrm{~d}$ of seed germination at the 11-leaf (rosette) stage and flowered within $41 \mathrm{~d}$ of seed sowing at the 16-leaf stage (Table 1). These data suggest that the ectopic expression of PSFT induced early flowering in transgenic $A$. thaliana.

To determine whether the early flowering phenotype was correlated with the high levels of the expression of PsFT in these transgenic plants, we analyzed expression of the Constans (CO), FT, Suppressor of overexpression of Constans1 (SOC1), Leafy ( $L F Y), A P 1$, and Apetala3 (AP3) genes in the controls and transgenic $A$. thaliana using RT-PCR. As shown in Figure 6, $P S F T$ expression was observed in $35 S:: P s F T$ transgenic plants but not in the WTs or vector controls. Low levels of $C O, F T$, $S O C 1, L F Y$, and $A P 1$ transcripts were observed at the two-leaf stage in the transgenic plants, and high levels of expression were observed at the four-leaf stage. AP3 was detected at a background level in the two-leaf stage in transgenic plants, and this level was increased at the four-leaf stage. However, no significant expression of $C O, F T, S O C 1, L F Y, A P 1$, or $A P 3$ was detected in the WT or vector control lines at the two-leaf or four-leaf stages. Thus, PsFT might promote the expression of $C O$ and the floral integrators $F T, S O C 1$, and $L F Y$ under LD conditions to further induce expression of $A P 1$ and $A P 3$, which are involved in floral induction.

The FT gene has been shown to effectively control flowering time and to be useful in accelerating the breeding of woody plants via transgenic approaches (Flachowsky et al., 2009). The overexpression of the $F T$-homologous gene of apple trees induces early flowering in $A$. thaliana and apple (Tränkner et al., 2010). The ectopic expression of an FT-like gene from Citrus confers early flowering in trifoliate orange plants (Endo et al., 2005). When juvenile poplars are transformed with poplar FT2, the first flowering is induced within 1 year (Hsu et al., 2006). In this work, we transformed PsFT into $A$. thaliana and analyzed the flowering genes in the transgenic plants. Our results suggest that $P S F T$ might be functionally conserved and serve the same purpose as A. thaliana FT in the regulation of flowering time. Once a transformation and regeneration system is established in Paeonia, PsFT may be useful in promoting the floral transition in tree peonies and be a valuable gene resource for modifying juvenility and thereby speeding up flowering and breeding programs for tree peonies. Furthermore, potential roles of PsFT in reblooming should be of particular use for extending the flowering period by manipulating the PsFT gene to induce the occurrence of reblooming in this ornamental crop.

\section{Literature Cited}

Abe, M., Y. Kobayashi, S. Yamamoto, Y. Daimon, A. Yamaguchi, Y. Ikeda, H. Ichinoki, M. Notaguchi, K. Goto, and T. Araki. 2005. FD, a bZIP protein mediating signals from the floral pathway integrator FT at the shoot apex. Science 309:1052-1056.

An, H.L., C. Roussot, P. Suarez-Lopez, L. Corbesler, C. Vincent, M. Pineiro, S. Hepworth, A. Mouradov, S. Justin, C. Turnbull, and G. Coupland. 2004. CONSTANS acts in the phloem to regulate a systemic signal that induces photoperiodic flowering of Arabidopsis. Development 131:3615-3626.

Barzilay, A., H. Zemah, R. Kamenetsky, and I. Ran. 2002. Annual life cycle and floral development of 'Sarah Bernhardt' peony in Israel. HortScience 37:300-303.

Böhlenius, H., T. Huang, L. Charbonnel-Campaa, A.M. Brunner, S. Jansson, S.H. Strauss, and O. Nilsson. 2006. CO/FT regulatory module controls timing of flowering and seasonal growth cessation in trees. Science 312:1040-1043.

Cheng, F.Y. 2007. Advances in the breeding of tree peonies and a cultivar system for the cultivar group. Intl. J. Plant Breeding 1:89104.

Chica, E.J. and L.G. Albrigo. 2013a. Changes in CsFT transcript abundance at the onset of low-temperature floral induction in sweet orange. J. Amer. Soc. Hort. Sci. 138:184-189.

Chica, E.J. and L.G. Albrigo. 2013b. Expression of flower promoting genes in sweet orange during floral inductive water deficits. J. Amer. Soc. Hort. Sci. 138:88-94.

Clough, S.J. and A.F. Bent. 1998. Floral dip: A simplified method for Agrobacterium- mediated transformation of Arabidopsis thaliana. Plant J. 16:735-743.

Endo, T., T. Shimada, H. Fujii, Y. Kobayashi, T. Araki, and M. Omura. 2005. Ectopic expression of an FT homolog from Citrus confers an early flowering phenotype on trifoliate orange (Poncirus trifoliata L. Raf.). Transgenic Res. 14:703-712.

Flachowsky, H., M.V. Hanke, A. Peil, S.H. Strauss, and M. Fladung. 2009. A review on transgenic approaches to accelerate breeding of woody plants. Plant Breed. 128:217-226.

Gilmore, B., N. Bassil, A. Nyberg, B. Knaus, D. Smith, D.L. Barney, and K. Hummer. 2013. Microsatellite marker development in peony using next generation sequencing. J. Amer. Soc. Hort. Sci. 138:64-74.

Hanzawa, Y., T. Money, and D. Bradley. 2005. A single amino acid converts a repressor to an activator of flowering. Proc. Natl. Acad. Sci. USA 102:7748-7753.

Hao, Q., N. Aoki, J. Katayama, T. Kako, K.S. Cheon, Y. Akazawa, and N. Kobayashi. 2013. Crossability of american tree peony 'High Noon' as seed parent with Japanese cultivars to breed superior cultivars. Euphytica 191:35-44.

He, G.M. and F.Y. Cheng. 2006. Morphological observation of sexual reproduction abortion in 'High Noon' tree peony. Acta Hort. Sinica 33:660-663.

Hsu, C.Y., Y. Liu, D.S. Luthe, and C. Yuceer. 2006. Poplar FT2 shortens the juvenile phase and promotes seasonal flowering. Plant Cell 18:1846-1861.

Huang, W., Z. Fang, S. Zeng, J. Zhang, K. Wu, Z. Chen, J.A.T. Silva, and J. Duan. 2012. Molecular cloning and functional analysis of three FLOWERING LOCUS T (FT) homologous genes from chinese cymbidium. Intl. J. Mol. Sci. 13:11385-11398.

Igasaki, T., Y. Watanabe, M. Nishiguchi, and N. Kotoda. 2008. The FLOWERING LOCUS T/TERMINAL FLOWER 1 family in lombardy poplar. Plant Cell Physiol. 49:291-300.

Jaeger, K.E. and P.A. Wigge. 2007. FT protein acts as a long-range signal in Arabidopsis. Curr. Biol. 17:1050-1054.

Jiang, Z., Z.A. Liu, L.S. Wang, and Q.Y. Shu. 2007. Relationship between the types of flower bud differentiation and forcing successive secondary flowering of tree peonies. Acta Hort. Sinica 3:683-687.

Kamenetsky, R., A. Barzilay, A. Erez, and A.H. Halevy. 2003. Temperature requirements for floral development of herbaceous peony $\mathrm{cv}$. 'Sarah Bernhardt'. Sci. Hort. 97:309-320.

Kardailsky, I., V.K. Shukla, J.H. Ahn, N. Dagenais, S.K. Christensen, J.T. Nguyen, J. Chory, M.J. Harrison, and D. Weigel. 1999. Activation tagging of the floral inducer FT. Science 286:1962-1965. Kikuchi, R., H. Kawahigashi, T. Ando, T. Tonooka, and H. Handa. 2009. Molecular and functional characterization of PEBP genes in barley reveal the diversification of their roles in flowering. Plant Physiol. 149:1341-1353.

Kittikorn, M., K. Okawa, H. Ohara, S. Kondo, N. Kotoda, M. Wada, M. Yokoyama, O. Ifuku, A. Murata, and N. Watanabe. 2013. Application 
of an analog of 9, 10- ketol-octadecadienoic acid (KODA), affected flower bud formation and MdTFL1 and MdFT1 gene expressions in apple buds under heavy-crop and shade conditions. J. Amer. Soc. Hort. Sci. 138:102-107.

Kotoda, N., H. Hayashi, M. Suzuki, M. Igarashi, Y. Hatsuyama, S. Kidou, T. Igasaki, M. Nishiguchi, K. Yano, T. Shimizu, S. Takahashi, H. Iwanami, S. Moriya, and K. Abe. 2010. Molecular characterization of FLOWERING LOCUS T-like genes of apple (Malus $\times$ domestica Borkh.). Plant Cell Physiol. 51:561-575.

Li, J.J., X.F. Zhang, and X.Q. Zhao. 2011. Tree peony of China. Encyclopedia of China Publishing House, Beijing, China.

Liu, Z.A., N. Aoki, N. Ito, and Y. Sakata. 2002. Flower-bud differentiation in Chinese tree peony cultivars and grown under protected cover (forced). J. Jpn. Soc. Hort. Sci. 71:818-825.

Livak, K.J. and T.D. Schmittgen. 2001. Analysis of relative gene expression data using real-time quantitative PCR and the $2^{-\triangle \Delta C T}$ method. Methods 25:402-408.

Parcy, F. 2005. Flowering: A time for integration. Intl. J. Dev. Biol. 49:585-593.

Perriere, G. and M. Gouy. 1996. WWW-query: An on-line retrieval system for biological sequence banks. Biochimie 78:364-369.

Pin, P.A. and O. Nilsson. 2012. The multifaceted roles of FLOWERING LOCUS T in plant development. Plant Cell Environ. 35:1742-1755.

Ren, X.L., H.F. Li, D.Q. Gong, and S.Y. Zhang. 2004. Effects of application of ethephon and $\mathrm{GA}_{3}$ in fall on bud sprouting and flowering of peony. Xibei Zhiwu Xuebao 5:895-898.

Rinne, P.L., A. Welling, J. Vahala, L. Ripel, R. Ruonala, J. Kangasjarvi, and C. van der Schoot. 2011. Chilling of dormant buds hyperinduces FLOWERING LOCUS T and recruits GA-inducible 1,3-beta-glucanases to reopen signal conduits and release dormancy in Populus. Plant Cell 23:130-146.

Simpson, G.G. and C. Dean. 2002. Arabidopsis, the rosetta stone of flowering time? Science 296:285-289.
Smith, D. 1997. Breeding tree peonies for fragrance. Paeonia 27:1-3. Tamura, K., D. Peterson, N. Peterson, G. Stecher, M. Nei, and S. Kumar. 2011. MEGA5: Molecular evolutionary genetics analysis using maximum likelihood, evolutionary distance, and maximum parsimony methods. Mol. Biol. Evol. 28:2731-2739.

Tränkner, C., S. Lehmann, H. Hoenicka, M.-V. Hanke, M. Fladung, D. Lenhardt, F. Dunemann, A. Gau, K. Schlangen, M. Malnoy, and H. Flachowsky. 2010. Over-expression of an FT-homologous gene of apple induces early flowering in annual and perennial plants. Planta 232:1309-1324.

Turck, F., F. Fornara, and G. Coupland. 2008. Regulation and identity of florigen: FLOWERING LOCUS T moves center stage. Annu. Rev. Plant Biol. 59:573-594.

Wang, Y.J., L. Dong, and C. Zhang. 2012. Reference gene selection for real-time quantitative PCR normalization in tree peony (Paeonia suffruticosa Andr.). J. Agr. Biotechnol. 20:521-528.

Wang, Z.Z. and Y.X. Zhang. 1987. Studies on morphogenesis and life cycle of the flower bud of tree peony (Paeonia suffruticosa Andr.). J. Shandong Agr. Univ. 3:9-16.

Wigge, P.A. 2011. FT, a mobile developmental signal in plants. Curr. Biol. 21:374-378.

Wister, J.C. 1962. The peonies. Amer. Hort. Soc., Washington, DC. Wu, J., C.C. Cai, F.Y. Cheng, H.L. Cui, and H. Zhou. 2014. Characterisation and development of EST-SSR markers in tree peony using transcriptome sequences. Mol. Breed. 4:1853-1866.

Zhang, H.L., D.E. Harry, C. Ma, C. Yuceer, C.Y. Hsu, V. Vikram, O. Shevchenko, E. Etherington, and S.H. Strauss. 2010. Precocious flowering in trees: The FLOWERING LOCUS T gene as a research and breeding tool in Populus. J. Expt. Bot. 61:2549-2560.

Zhou, H., F.Y. Cheng, R. Wang, Y. Zhong, and C.Y. He. 2013. Transcriptome comparison reveals key candidate genes responsible for the unusual reblooming trait in tree peonies. PLoS ONE 8: e79996. 


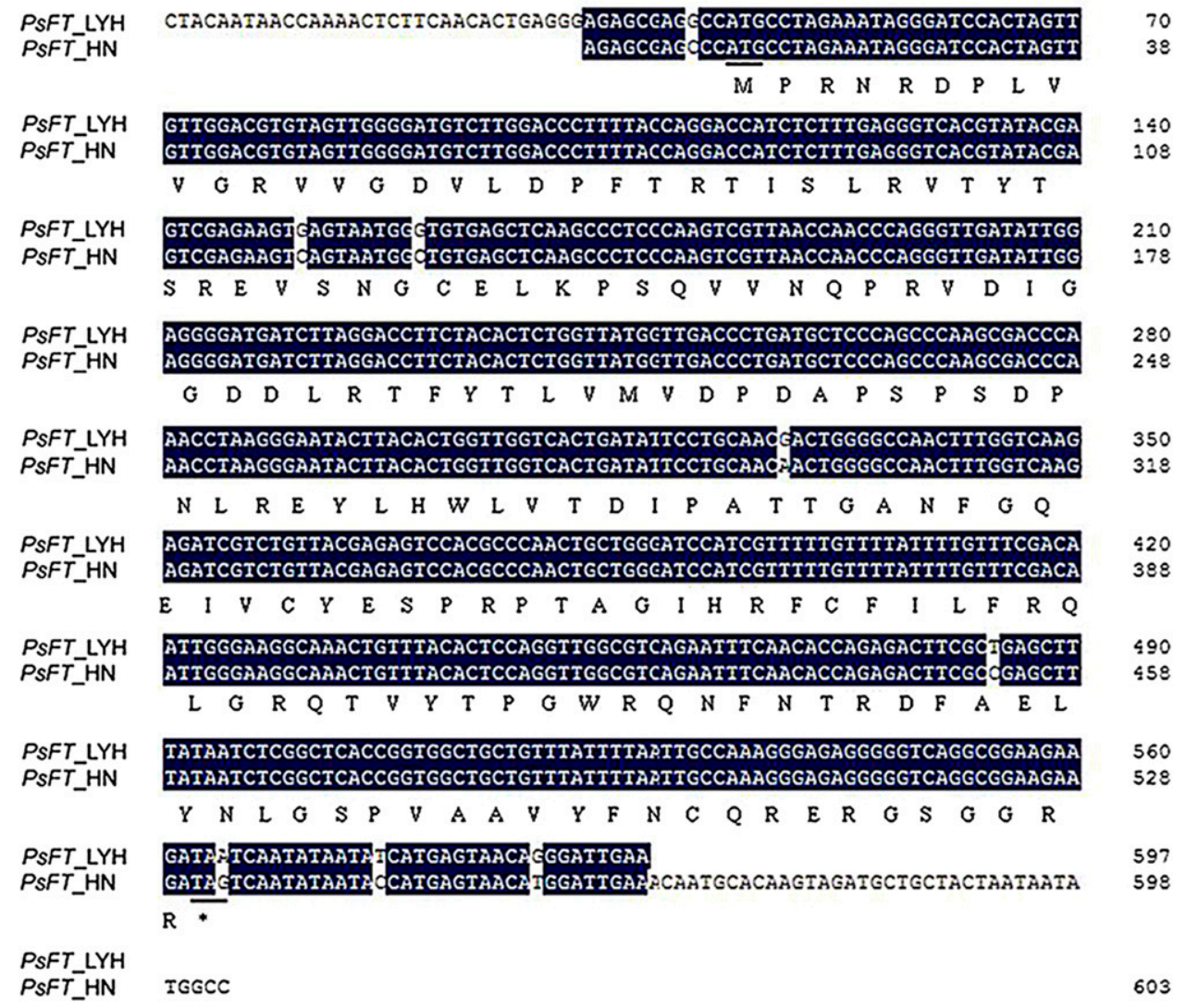

Supplemental Fig. 1. Comparison of the two full-length PsFT cDNAs from the $P$. $\times$ lemoinei 'High Noon' (HN) and $P$. $\times$ suffruticosa 'Luo Yang Hong' (LYH). The underlined portions represent the initiation codons (ATG) and termination codons (TAG and TAA). The deduced protein sequences are shown here. 
Supplemental Table 1. Primers used in this study.

\begin{tabular}{|c|c|c|c|}
\hline Primers & Sequences $\left(5^{\prime} \rightarrow 3^{\prime}\right)$ & $\begin{array}{c}\text { Annealing } \\
\text { temperature }\left({ }^{\circ} \mathrm{C}\right)\end{array}$ & $\begin{array}{c}\text { Fragment } \\
\text { size (bp) }\end{array}$ \\
\hline$P s F T-\mathrm{F}(\mathrm{HN})$ & GGGAAGGGAGGAAGAGC & 54 & 604 \\
\hline$P s F T-\mathrm{R}(\mathrm{HN})$ & GGGCCATATTATTAGTAGCAG & & \\
\hline$P S F T-\mathrm{R}(\mathrm{LYH})$ & TTCAATCCCTGTTACTCAT & & \\
\hline$P S F T-\mathrm{F}$ (real time) & GTGTAGTTGGGGATGTCTTGGA & 55 & 210 \\
\hline$P S F T$-R (real time) & TTAGGTTTGGGTCGCTTGG & & \\
\hline$P s U B Q-\mathrm{R}$ (real time) & CGTTCCAGCACCACAATC & & \\
\hline PsGAPDH-F (real time) & GGTTGATCTCACTGTTAGGC & 55 & 151 \\
\hline$P s G A P D H-\mathrm{R}$ (real time) & TCAGACTCСТCССТАCAAG & & \\
\hline $\mathrm{M} 13 \mathrm{~F}$ & GTTTTCCCAGTCACGAC & & \\
\hline M13R & GCGGATAACAATTTCACACAGG & & \\
\hline$P S F T-\mathrm{F}(X b a \mathrm{I})$ & GCTCTAGAATGCCTAGAAATAGGGATCCAC & 65 & 542 \\
\hline$F T$-R & TAGGCATCATCACCGTTCGT & & \\
\hline SOC1-F (AY007726) & ATGGTGAGGGGCAAAACTC & 56 & 645 \\
\hline SOC1-R & TCACTTTCTTGAAGAACAAGG & & \\
\hline$L F Y$-F (NM_125579.1) & TGAAGGACGAGGAGCTT & 56 & 511 \\
\hline$L F Y-\mathrm{R}$ & TTGCCACGTGCCACTTC & & \\
\hline APl-F (NM_105581) & CATTATCTTGGGGAAGACTTGCAAG & 56 & 450 \\
\hline$A P 1-\mathrm{R}$ & GGAAATGCTTCATGCGGCGAAGC & & \\
\hline AP3-F (NM_115294) & GCTTGACATTCAGGAGCTGCGTCG & 56 & 396 \\
\hline$A P 3-\mathrm{R}$ & TAGATAGACAATGATGGCACCAGC & & \\
\hline$U Q B-\mathrm{F}$ (NM_116090.2) & GTGGTGCTAAGAAGAGGAAGA & 53 & 251 \\
\hline$U Q B-\mathrm{R}$ & TCAAGCTTCAACTTCTTCTTT & & \\
\hline
\end{tabular}

$\overline{P S F T}=$ Flowering locus $T$ in tree peonies; $P S U B Q=$ Ubiquitin in tree peonies; $P s G A P D H=$ Glyceraldehyde-3-phosphate-dehydrogenase in tree peonies; $C O=$ Constans; $F T=$ Flowering locus $T ; S O C 1=$ Suppressor of Overexpression of Constans $1 ; L F Y=$ Leafy; AP1 = Apetala1; AP3 = Apetala3; $U B Q=$ Ubiquitin. 